\title{
Design, fabrication and characterization of a novel 3D force sensor made of SU-8
}

A. Jordan, A. Phataralaoha, A. Tibrewala, S. Büttgenbach

Institut für Mikrotechnik, Technische Universität Braunschweig

Alte Salzdahlumer Str. 203, 38124 Braunschweig, Germany

This work presents an innovative approach to develop highly sensitive piezoresistive 3D force sensors made of SU-8 photoresist and diamond-like carbon (DLC). Therefore a low cost fabrication process is developed accompanied by design studies and an estimation of mechanical properties of the deforming elements. The results of this study provide a comparison between characteristics of 3D force sensors made of SU-8 and silicon.

The novel SU-8 force sensor design is based on an SU-8 boss-membrane with piezoresistive elements of DLC. It is chosen in order to compare the sensor characteristics with a conventional force sensor made of silicon ( $\mathrm{Si}$ ) with diffused piezoresistors. The approach reported here differs from previous work of other groups $[1,2,6]$ in the force sensor geometry and in the strain sensitive material. Instead of a composite film of SU-8 and carbon black particles [2], the intention is to apply thin films of sputter deposited amorphous carbon (a-C) [3] and plasma assisted chemical vapour deposited (PA$\mathrm{CVD})$ hydrogenated amorphous carbon $(\mathrm{a}-\mathrm{C}: \mathrm{H})$ as strain sensitive material. The fabrication process of the SU-8 deforming elements following [6] was adapted to process requirements to fabricate SU-8 membranes with thickness $t$ in the range of $25 \mu \mathrm{m}<t<100 \mu \mathrm{m}$. This paper will present a selected set of test results on the characterization of the Si force sensor as well as simulations and analytical results on the characterization of the comparably designed SU-8 force sensor.

The working principle of the presented Si 3D force sensor, as well as typical membrane designs and a measurement set up are reported in $[4,5]$. As tactile element, an approximately $5 \mathrm{~mm}$ long stylus of tungston carbide (WC) with a ruby probing ball of $300 \mu \mathrm{m}$ diameter, attached to the center of the membrane, is used (see figure 1). The piezoresistive elements are fabricated on the backside of the membrane at four positions located near the points of maximum stress. They are arranged as Wheatstone bridges to increase the sensitivity and to eliminate temperature effects on the output signal. Probing a measurement object with the probing ball produces deflection and deformation of the membrane caused by the probing force. This will lead to mechanical stress in the membrane dependent upon the direction of load. The difference in stress condition is in turn utilized to detect the direction of load.

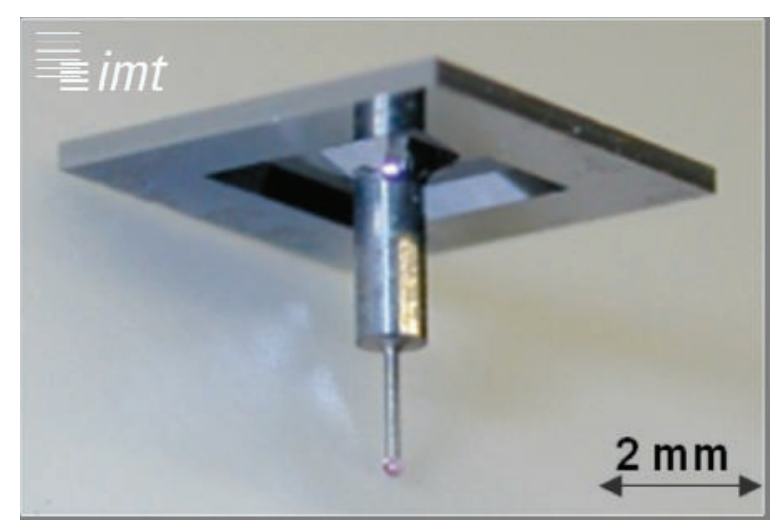

Figure 1. Design of the silicon 3D force sensor 
The design of the SU-8 force sensor (see figure 2) is chosen in order to compare the sensor characteristics with a force sensor made of $\mathrm{Si}$ of $25 \mu \mathrm{m}$ thickness. The silicon probe is based on a boss membrane made from single crystalline Si by means of anisotropic etching using potassium hydroxide $(\mathrm{KOH})$. Fabrication of the SU-8 probe begins with substrate preparation and deposition of a sacrificial layer. The subsequent patterning of contacts and piezoresistors is followed by three levels of photolithography to pattern the SU-8 structural layers. To obtain comparably results in bending stiffness and displacement of the stylus, a higher membrane thickness for the SU-8 deforming elements up to $100 \mu \mathrm{m}$ is to be used. Table 1 shows the bending stiffness for two different membrane designs, namely single-boss full membrane and cross membrane, using Si and SU-8 as sensor material, respectively.

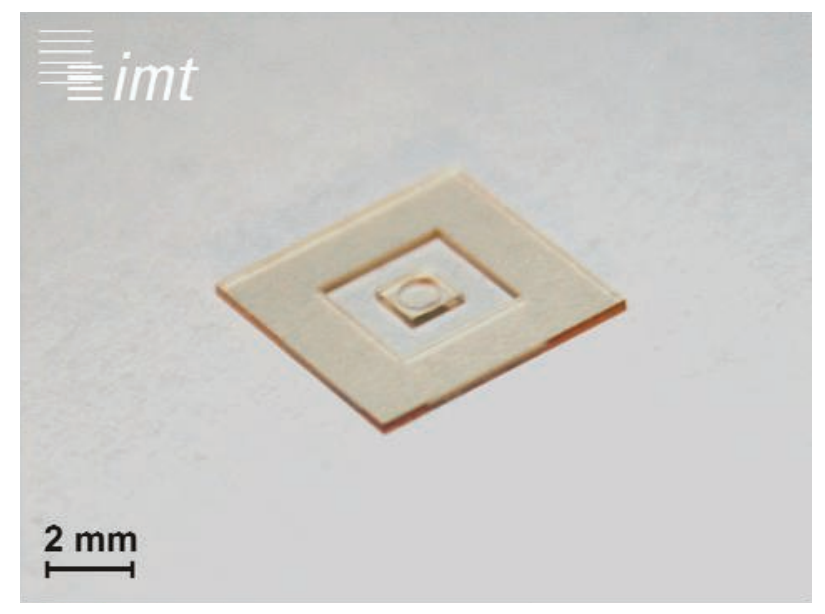

Figure 2. SU-8 sensor design with membrane thickness $t=50 \mu \mathrm{m}$

In Table 2 the breaking points as test results and numerical results for Si and SU-8, respectively, are presented. As failure criterion for SU-8 a maximum allowable stress of $3.5 \cdot 10^{7} \mathrm{~Pa}$ was assumed. Regarding the achievable maximum force at all spatial directions, it is considerably higher for SU-8. Figure 3 and figure 4 show displacement vs. thickness plots for Si and SU-8, respectively.

Table 1. Bending stiffness for silicon (measured) and SU-8 (simulated); two membrane designs

\begin{tabular}{|c|c|c|c|c|}
\hline \multirow{2}{*}{$\begin{array}{c}\text { force sensor } \\
\text { geometry }\end{array}$} & $\begin{array}{c}\text { Si; } 25 \mu \mathrm{m} \\
\text { (vertical deflection) }\end{array}$ & $\begin{array}{c}\text { Si; } 25 \mu \mathrm{m} \\
\text { (lateral deflection) }\end{array}$ & $\begin{array}{c}\text { SU-8; } 100 \mu \mathrm{m} \\
\text { (vertical deflection) }\end{array}$ & $\begin{array}{c}\text { SU-8; } 100 \mu \mathrm{m} \\
\text { (lateral deflection) }\end{array}$ \\
\hline $\begin{array}{c}\text { single boss } \\
\text { full membrane }\end{array}$ & 12.39 & 0.40 & 25.91 & 0.45 \\
\hline $\begin{array}{c}\text { single boss } \\
\text { cross membrane }\end{array}$ & 7.71 & 0.32 & 20.43 & 0.38 \\
\hline
\end{tabular}

Table 2. $\quad$ Breaking point for silicon (measured) and SU-8 (simulated)

\begin{tabular}{|c|c|c|c|c|}
\hline \multirow{2}{*}{ breaking point } & \multicolumn{2}{|c|}{ vertical load } & \multicolumn{2}{|c|}{ lateral load } \\
\cline { 2 - 5 } & $\begin{array}{c}\text { max. displacement } \\
{[\mu \mathrm{m}]}\end{array}$ & max. force $[\mathrm{mN}]$ & $\begin{array}{c}\text { max. displacement } \\
{[\mu \mathrm{m}]}\end{array}$ & 140.0 \\
\hline $\begin{array}{c}\text { Si; } 25 \mu \mathrm{m} \\
\text { full membrane }\end{array}$ & 30.0 & 150 & 168.5 & 30 \\
\hline $\begin{array}{c}\text { SU-8; } 100 \mu \mathrm{m} \\
\text { full membrane }\end{array}$ & 30.9 & 800 & 75 \\
\hline
\end{tabular}




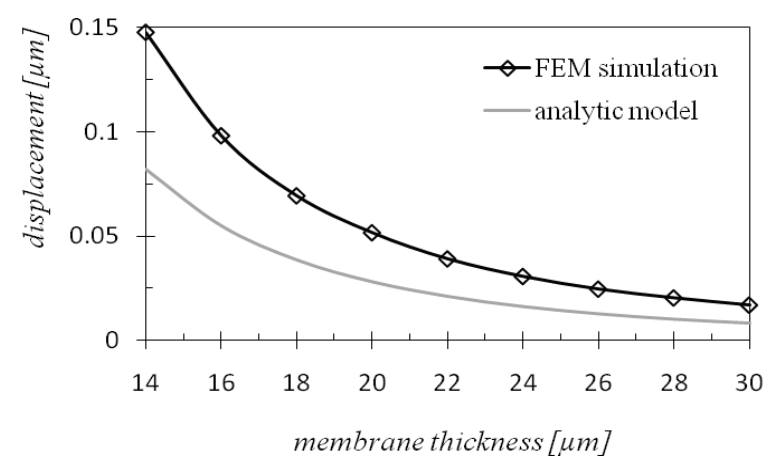

Figure 3. Calculated displacement vs. membrane thickness of silicon boss membrane at a vertical load of $F=1 \mathrm{mN}$; the light grey line represents the analytical method while the black line with markers represents the numerical results.

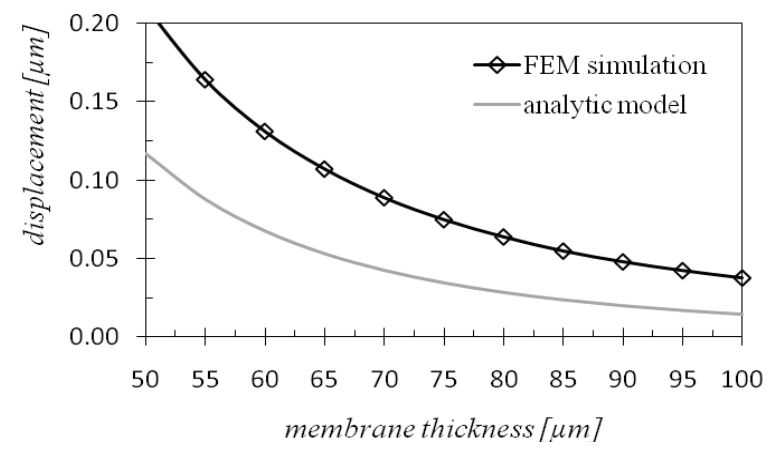

Figure 4. Calculated displacement vs. membrane thickness of SU-8 boss membrane at a vertical load of $F=1 \mathrm{mN}$; the light grey line represents the analytical method while the black line with markers represents the numerical results.

The FEM simulated results are superior to the analytical values consistent with the test results. The curve shapes represent the displacement at a vertical load of $F=1 \mathrm{mN}$. In the event of a lateral load, distinguishing values of about $1 \mu \mathrm{m}$ displacement at $26 \mu \mathrm{m}$ thickness (silicon) and of $8.7 \mu \mathrm{m}$ displacement at $50 \mu \mathrm{m}$ thickness (SU-8) can be found. The mechanical stress along the membrane axis is analysed (see figure 5). The standardized curve mapped for SU-8 (see figure 6) reveals deviations from the ideal linear shape at a membrane thickness lower than $35 \mu \mathrm{m}$, affected by the high displacement. In the event of an equal lateral load, the stress maxima reach 10 times higher values compared to the stress at vertical load.

The combination of SU-8 and DLC, due to low Young's modulus and high gauge factors, respectively, promises sensitivity much higher than what is obtained using conventional silicon force sensors. The presented results provide great opportunities to adjust the characteristics of the innovative SU-8 force sensor to obtain an ideal sensor design. 


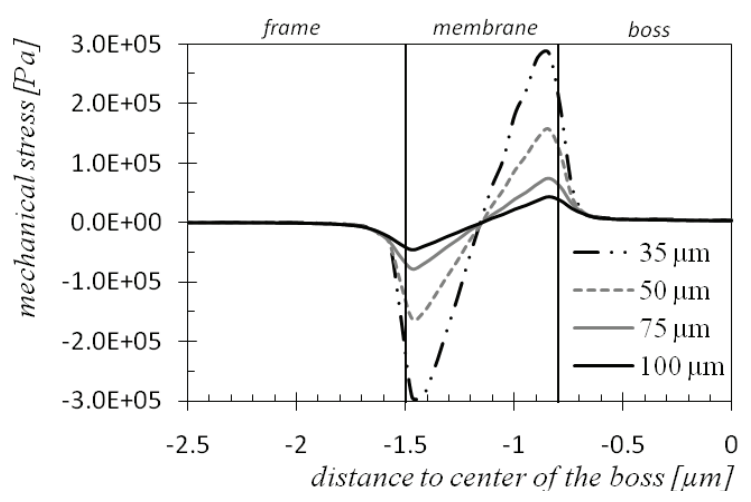

Figure 5. Mechanical stress along the SU-8 membrane axis at a vertical load of $F=1 \mathrm{mN}$; the lines characterize different membrane thicknesses.

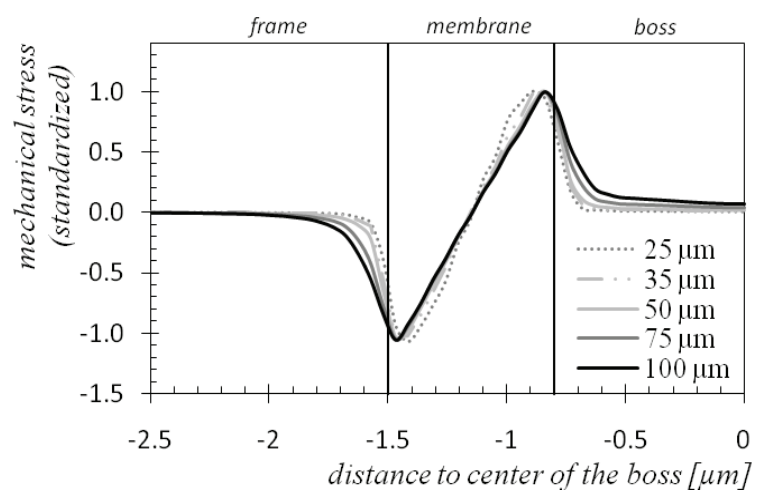

Figure 6. Standardized mechanical stress along the SU-8 membrane axis; the lines characterize different membrane thicknesses.

\section{Acknowledgments}

The support of the Deutsche Forschungsgemeinschaft (DFG) is gratefully acknowledged.

\section{References}

[1] L. Gammelgaard, P.A. Rasmussen, M. Calleja, P. Vettiger, A. Boisen, Applied Physics Letters, 88 (11), art. no. 113508, (2006).

[2] V. Seena, A. Rajoriya, A. Fernandes, K. Dhale, P. Pant, S. Mukherji, V.R. Rao, Proc. of MEMS 2010, art. no. 5442340, pp. 851-854, (2010).

[3] E. Peiner, A. Tibrewala, R. Bandorf, H. Lüthje, L. Doering, W. Limmer, Journal of Micromechanics and Microengineering, 17 (7), art. no. S04, pp. S83-S90, (2007).

[4] A. Tibrewala, N. Hofmann, A. Phataralaoha, G. Jäger, S. Büttgenbach, Sensors, 9 (5), pp. 32283239, (2009).

[5] A. Tibrewala, A. Phataralaoha, S. Büttgenbach, Journal of Micromechanics and Microengineering, 19 (12), art. no. 125005, (2009).

[6] J. Hammacher, A. Fuelle, J. Flaemig, J. Saupe, B. Loechel, J. Grimm, Microsystem Technologies, (9-11), pp. 1515-1523, (2008). 